\title{
The Shape Memory Phenomenon: An Intrinsic Feature of Materials after Programming
}

\section{WM Huang*}

\author{
School of Mechanical and Aerospace Engineering, Nanyang Technological University, Singapore
}

${ }^{*}$ Corresponding author: Wei Min Huang, Associate Professor, School of Mechanical and Aerospace Engineering, Nanyang Technological University, 50 Nanyang Avenue, 639798, Singapore, Fax: 0065 67924062, Tel: 0065 67904859, E-mail: mwmhuang@ntu.edu.sg

Citation: WM Huang (2013) The Shape Memory Phenomenon: An Intrinsic Feature of Materials after Programming. J Mater Sci Nanotechnol 1(1): e103. doi: 10.15744/2348-9812.1.e103

Received Date: June 23, 2013 Accepted Date: July 29, 2013 Published Date: August 01, 2013

Naturally, all materials are able to response to some particular stimuli via changing their one or more chemical/physical properties accordingly. Among these properties, the ability for shape change can be harnessed for motion and/or force generation. There are two basic ways to response to the present of the right stimulus (such as heating/cooling, light, chemical/ solvent etc), one is spontaneous (either instantly in an elastic manner or gradually in a viscous-elastic fashion, while the other requires additional driving force by means of applying the right external stimulus to trigger recovery back to the original shape. Correspondingly, the former phenomenon is called the Shape Change Effect (SCE), while the latter is called the Shape Memory Effect (SME) [1,2].

Although the SCE has been well-known long time ago and has been utilized in various applications for years, until now, the SME is seemingly still considered as a surprise phenomenon observable only in some particular materials. Is the SME a unique phenomenon of some particular materials or an intrinsic feature of materials?

While the term of SME was most likely coined after the phenomenon was observed in AuCd in 1932, heat shrinkable polymer (heating-responsive SME) has actually been used well before this term emerged [3]. On the other hand, in addition to conventional Shape Memory Materials (SMMs), (e.g., shape memory alloy (SMA), in which there are some strict crystal symmetry conditions [4,5], shape memory polymer (SMP), Shape Memory Gel (SMG), shape memory ceramic $(\mathrm{SMC}))[3,6,7]$, various other mechanisms have been reported to achieve the SME in a range of conventional materials. For instance, collapse of dislocation loops during annealing causes the disappearance of an indent atop a zinc crystal [8]; molecular simulation reveals the SME in metal nanowires [9]; utilizing silicone and wax, in which silicone severs as the elastic matrix and wax as the transition inclusion, the SME has been reported in the resulted hybrid [3].

According to the working mechanisms proposed in [2], all polymeric materials have the heating-responsive and chemo- responsive SME. Furthermore, the SME may be extended into many other materials according to some generic working mechanisms reported in [10]. For examples, we can realize the heating-responsive SME in solder and melting glue [2]; cooling- and water-responsive SME in a hybrid made of Poloxamer 407 gel and elastic sponge [11].

Now, in addition to our previous understanding that the SME requires a programming process to setup a temporary shape [12], we may apply some generic working mechanisms to enable the SME in a material (hence the SME may be considered as an intrinsic feature of materials), to design a SMM with the required feature(s), and to optimize the performance of a particular SMM.

Given above seemingly new features, we expect to see even greater impact that the shape memory phenomenon will bring forward to our life, not only for actuation as in traditional applications, but also as a new fabrication technique and even a reliable compact sensor.

\section{References}

1. Lendlein A (2010) Shape-memory Polymers. Springer, New york, USA .

2. Huang WM, Zhao Y, Wang CC, Ding Z, Purnawali H, et al. (2012) Thermo/ chemo responsive shape memory effect in polymers: a sketch of working mechanisms, fundamentals and optimization. J Polym Res 19: 9952.

3. Sun L, Huang WM, Ding Z, Zhao Y, Wang CC, et al. (2012) Stimulusresponsive shape memory materials: A review. Mater Des 33: 577-640.

4. Bhattacharya K, Conti S, Zanzotto G, Zimmer J (2004) Crystal symmetry and the reversibility of martensitic transformations. Nature: 428: 55-59.

5. Huang X, Ackland GJ, Rabe KM (2003) Crystal structures and shapememory behaviour of NiTi. Nat Mater 2: 307-311.

6. Huang WM, Ding Z, Wang CC, Wei J, Zhao Y, et al. (2010) Shape memory materials. Mater Today 13: 54-61.

7. Otsuka K, Wayman CM (1998) Shape memory materials. Cambridge University Press, Cambridge, England.

8. Washburn J (1956) Experimental observations concerning the collapse of dislocation loops during annealing. Minerals Research Laboratory, North Carolina, USA. 
9. Park HS, Gall K, Zimmerman JA (2005) Shape memory and pseudoelasticity in metal nanowires. Phys Rev Lett 95: 255504

10. Huang WM, Song CL, Fu YQ, Wang CC, Zhao Y, et al. (2013) Shaping tissue with shape memory materials. Adv Drug Deliv Rev 65: 515-535.

11. Wang CC, Huang WM, Ding Z, Zhao Y, Purnawali H (2012) Cooling-/ water-responsive shape memory hybrids. Composites Science and Technology 72: $1178-1182$
12. Lendlein A, Kelch S (2002) Shape-memory polymers. Angew Chem Int Ed 41: 2034-2057.

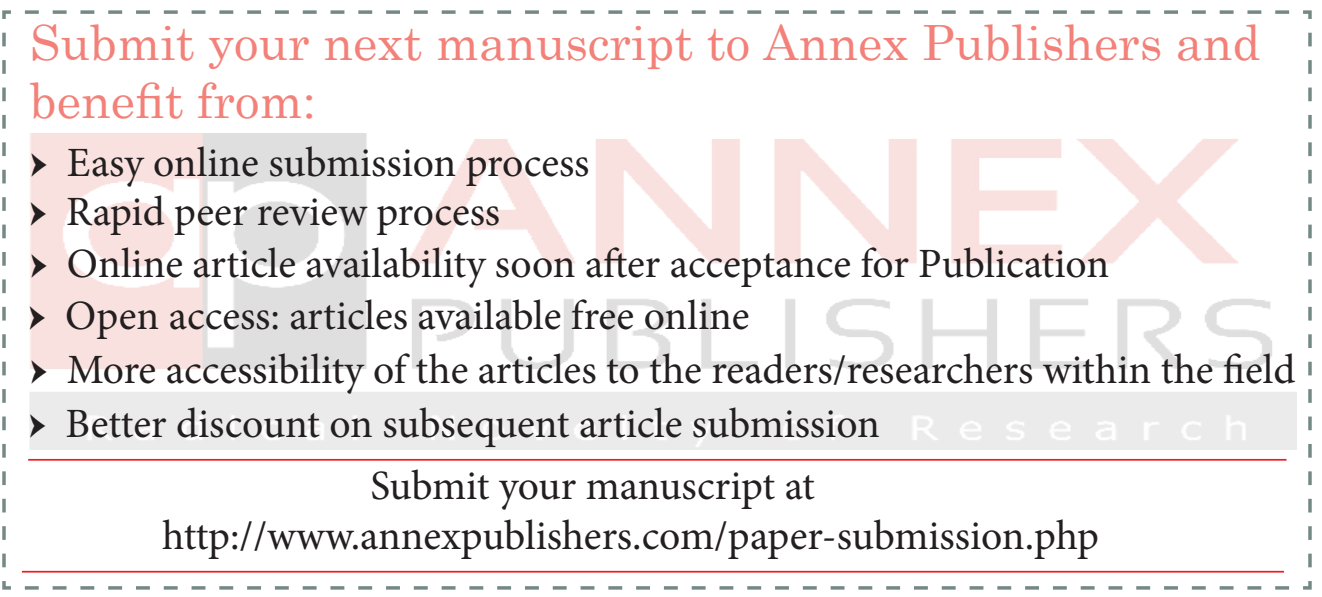

